\title{
Capsule Commentary on Jones et al., Usual Primary Care Provider Characteristics of a Patient-Centered Medical Home and Mental Health Service Use
}

\author{
Steven Vannoy, $\mathrm{PhD}, \mathrm{MPH}$ \\ University of Massachusetts Boston, Boston, MA, USA. \\ J Gen Intern Med 30(12): 1854 \\ DOI: $10.1007 / \mathrm{s} 11606-015-3455-7$ \\ (c) Society of General Internal Medicine 2015
}

$\mathrm{M}$ ental health care is commonly provided in primary care, a trend likely bolstered by the Affordable Care Act (ACA). ${ }^{1}$ There have been more than 80 randomized trials demonstrating the effectiveness of the collaborative care (CC) model for mental health care. ${ }^{2}$ Based on the overlapping components of the Patient Centered Medical Home and CC, it is reasonable to expect similar improvement in mental health treatment in systems delivering PCMH care.

The article by Jones et al. supports the notion that PCMH will increase mental health services (MHS) utilization, and elucidates what may be important component-level factors and their relationship to the amount and quality of MHS. ${ }^{3}$ By separating providers into "usual care" and "PCMH," Jones et al. demonstrate that having a usual provider boosts mental health service utilization by a factor of two; having a PCMH provider does not increase mental health service utilization beyond that. While getting people in the door is certainly necessary, decades of mental health services research demonstrate that it is not sufficient to improve patient outcomes. To get that, one must change both provider and system factors. Jones et al. found that patients with PCMH providers were more likely to receive counseling and to have visited a mental health professional. This suggests that PCMH providers are facilitating access to multiple levels and modalities of care, which are likely more effective for a broader range of mental

This comment refers to the article available at: $h$ ttp://dx.doi.org/10.1007/ s11606-015-3417-0.

Published online July 1, 2015 health distress. The sensitivity analysis provides strong evidence that the more PCMH qualities offered, the better the outcome.

Consistent with this concept, there is a strong relationship between provider and patient on response to treatment. ${ }^{4}$ Jones et al. show us this may likely be the case in PC-based mental health treatment as well. However, compared to traditional psychotherapy practice, PCPs are extremely limited in time and training for delivering evidence-based psychological treatment. Thus, PCPs must rely on adjunctive treatment resources and systemic support. Jones et al. highlight that this is likely happening with PCMH providers. While this is exciting, disparity in access to both usual and PCMH care remains an important limitation for patients.

Whether the ACA will reduce some of these disparities remains to be seen.

Conflict of Interest: The author has no conflicts of interest with regard to this article.

Corresponding Author: Steven Vannoy, $\mathrm{PhD}, \mathrm{MPH}$; University of Massachusetts Boston, Boston, MA, USA (e-mail: steven.vannoy@umb.edu).

\section{REFERENCES}

1. Beronio K, Po R, Skopec L, et al. Affordable Care Act Expands Mental Health and Substance Use Disorder Benefits and Federal Parity Protections for 62 Million Americans (Washington, D.C.: Office of the Assistant Secretary for Planning and Evaluation, 2013)

2. Jones AL, Cochran SD, Leibowitz A, Wells KB, Kominski G, Mayes VM. Usual Primary Care Provider Characteristics of a Patient-Centered Medical Home and Mental Health Service Use. J Gen Intern Med. 2015. doi:10. 1007/s11606-015-3417-0.

3. Archer J, Bower P, Gilbody S, Lovell K, Richards D, Gask L, Dickens C, Coventry P. Collaborative care for depression and anxiety problems. Cochrane Database of Systematic Reviews 2012, Issue 10. Art. No.: CD006525. DOI: 10.1002/14651858.CD006525.pub2

4. Wampold BE, Imel ZE. The Great Psychotherapy Debate: The Evidence for What Makes Psychotherapy Work. Taylor \& Francis; 2015. 